Quaestio facti. Revista Internacional sobre Razonamiento Probatorio Quaestio facti. International Journal on Evidential Legal Reasoning Sección: Conjeturas y refutaciones N. 2 | 2021 pp. $285-298$ Madrid, 2021 DOI: $10.33115 /$ udg_bib/qf.i2.22455 Marcial Pons Ediciones Jurídicas y Sociales (C) David Enoch ISSN: 2604-6202

Recibido: 27/05/2020 | Aceptado: 04/08/2020 | Publicado: 01/01/2021 Editado bajo licencia Reconocimiento 4.0 Internacional de Creative Commons

\title{
HOW TO THEORIZE ABOUT STATISTICAL EVIDENCE (AND REALLY, ABOUT EVERYTHING ELSE): A COMMENT ON ALLEN
}

David Enoch

The Philosophy Department and the Faculty of Law The Hebrew University of Jerusalem. David.Enoch@mail.huji.ac.il

ABSTRACT: In responding to Prof. Allen's paper, I make several general methodological points: about the use of hypothetical cases, about the point of theorizing, and about the role of idealization. Then I make some more specific points about his claims about (and against) previous work on statistical evidence.

KEYWORDS: legal epistemology; statistical evidence; legal theory.

SUMARY: 1. SEVERAL ISSUES SET ASIDE.-2. WHAT'S THE POINT?--3 WEIRD HYPOTHETICAL CASES.- 4. MORE ON STATISTICAL EVIDENCE: 4.1. How does the law treat statistical evidence?. 4.2. Sensitivity. 4.3. Incentives.-5. CONCLUSION.-6. BIBLIOGRAPHY.

RECOMMENDED CITATION: ENOCH, DAVID, 2020: «How to Theorize about Statistical Evidence (and Really, about Everything Else): A comment on Allen", in Quaestio facti, 2: 285-298. Madrid: Marcial Pons Ediciones Jurídicas y Sociales. DOI: http://dx.doi.org/10.33115/udg_bib/ qf.i2.22455 
I want to thank Ronald Allen for giving such close attention to my and my co-authors' work on statistical evidence ${ }^{1}$. I also want to start by noting how successful his piece is in at least one of his stated goals - namely, to be provocative.

Revisiting the central theme from Allen and Leiter (2001), Allen insists that internalizing the lessons from naturalized epistemology-presumably, primarily against a priori reasoning and for more empirically minded research of, well, everything - undermines a whole body of literature in the theory of evidence law: discussions of statistical evidence, and what, if anything, makes this kind of evidence more suspicious than other, direct, non-statistical evidence. Allen is strongly critical of a priori reasoning about this and related problems, the kind of reasoning that is not sensitive to the dynamic and complex nature of the American legal system, and that is of no help to the jurist. Central to his arguments is a sustained criticism of relying on "weird hypotheticals»— cases from which nothing of value can, he seems to think, be learned. Though my and my co-authors' work on these matters is unsurprisingly especially dear to my heart, I think it's safe to say that it plays merely the role of a (central) example in Allen's paper, which seeks to establish a more general conclusion, namely, that at least in so far as we're interested in helping the jurist understand the American legal system, this kind of research program is entirely misguided.

Here's my plan for this comment. in the first section, I flag several claims that I will not be taking issue with here. In section 2, I comment on what I take to be the point of theorizing about statistical evidence-the answer I give to this question seems to be very different from the one Allen takes for granted. In section 3, I discuss specifically Allen's rejection of "weird hypotheticals», a discussion that leads to a more general one, of the role of idealization in theorizing. These two sections are, then, both methodological, and entirely general-they do not amount to a specific defense of my own views about statistical evidence (though they're relevant for such a defense, of course). Indeed, they're even more general than that: the methodological picture I sketch applies, as far as I can see, to any theorizing effort, and because I think it is almost obvious, I wouldn't have bothered the reader with it if Allen's text hadn't so clearly called for it. In section 4, I quickly comment on some more specific points Allen makes about our views of statistical evidence.

\section{SEVERAL ISSUES SET ASIDE}

I will not be using the phrase «naturalizing epistemology». This phrase-as Allen notes- has come to mean different things, perhaps (he doesn't say that) to the

1 The relevant papers are all co-authored, with either Talia Fisher, or Levi Spectre, or both. See Enoch, Spectre and Fisher (2012), Enoch and Fisher (2015), and Enoch and Spectre (2019). I thank Tali and Levi also for reading and commenting on this paper. I also thank a reader for Quaestio Facti. 
point where it's no longer helpful. When he explains what he has in mind with that phrase he mentions two central commitments: first, a commitment to something like «ought-implies-can», the relation of which to standard philosophical discussions of naturalizing epistemology I do not see (and a commitment which, for the most part, and after suitable qualifications, I share); and second, something about «the difference between a priori conceptual/normative analysis on the one hand and on the other empirical inquiry into the actual state of some phenomena». I am going to set aside general worries-not just about what naturalizing epistemology is, but also about whether we should naturalize epistemology (for the record, I think that the only senses in which we should are senses that render this claim trivial), and indeed about the relevant nature of Allen's project (he seems to recommend abandoning a priori normative discourse, seemingly equally enthusiastic both for rejecting normative discourse and for engaging it, making recommendations, etc.). As far as I can see, all the interesting topics in Allen's paper can be stated and discussed without the catch-phrase (in some circles) «naturalizing epistemology».

Second, Allen is out to reject a probabilistic conception of legal evidence (though he also seems to think it's a dead horse he's beating, talking of «the demise of the probabilistic explanation»). I am not defending such a conception, and I am certainly not making any claims about the history of evidence law and evidence law theory. I do think-how can one not? - that something about probabilities is often very relevant to any plausible conception of evidence, so that dismissing the relevance of the probability calculus entirely when commenting on legal evidence is unjustified. (Some of what Allen says seems to pull in that direction). But I am certainly not committed to the claim that the probability calculus is the only game in town ${ }^{2}$.

Third, I will not be commenting here on «relative plausibility theory», the alternative view of legal evidence that Allen sketches here (and develops in detail elsewhere). While I have some worries about it ${ }^{3}$, I don't know it well enough to comment seriously about it, and my focus in this comment lies elsewhere.

\section{WHAT'S THE POINT?}

What are we after, when we're theorizing about statistical evidence? What is the point of such theorizing? There needn't be a single, privileged, canonical point, of course. Different theorists may be after different things. But Allen is explicit about what it is that he is after. He is after «...understanding juridical proof from the inside...». And while this wording may not be sufficiently clear, when he criticizes some of his targets Allen is clearer, saying such things as that the target views fail

2 It's not clear to me how exactly Allen is using the term "reductionism", but what I say in the text here may amount to agreeing with him about rejecting reductionism, or a specific version thereof.

${ }^{3}$ Chief among them is the thought that talk of relative plausibility amounts not to a solution to any problem, but rather to renaming it. 
«... if the objective is to understand the actual state of the subject of the inquiry-to help us jurists in other words». But while helping people—jurists or otherwise-is often a good idea, I fail to recognize my aim in these words.

When I theorize-about statistical evidence, or about anything else-the aim is to reach knowledge and understanding of important relevant truths. The aim, in other words, is entirely epistemic. The questions I ask about some suggested theory of statistical evidence are questions like: Is it true? Is it enlightening? Does it promote insight into the nature of statistical evidence, and indeed evidence more generally? Are the arguments supporting it convincing? Does the theory have problematic implications elsewhere in our system of beliefs? And while it may be nice if an Ameri$\mathrm{can}^{4}$ lawyer or judge somewhere shows interest in my paper, this is not an adequacy constraint on a theoretical paper, and it certainly isn't the point of such theorizing.

The water here may be muddied by Allen's use of the word «jurist». «Jurist» may mean anyone thinking about the law. In this sense, jurists should of course be interested in greater knowledge and understanding, and so in this sense, theorizing (in my sense) does help jurists. In another sense ${ }^{5}$, though, «jurist» just means the practitioner, a lawyer or a judge. Practitioners too, however, may be interested in greater understanding - not necessarily for understanding's instrumental payoffs, if there are any, but because practitioners too may be reflective and sophisticated, and if they are, a good theory (one that facilitates knowledge and understanding) does help them. The only kind of jurist for whom such understanding is nothing is the narrow-minded, what's-in-it-for-the-way-I-argue-my-next-case kind of practition$e^{6}{ }^{6}$. I fully acknowledge that what I say about statistical evidence may not give the

4 Throughout the paper, Allen talks specifically about the American legal system (if my app is right, the word «American» appears in his paper 27 times). This seems to me like the academic analogue of American exceptionalism - a less dangerous exceptionalism than many others, of course, but not a nicer or better-supported one. A theory of statistical evidence is - at least if all goes well-an attempt to understand statistical evidence in general, not in some specific jurisdiction. Even if it's about helping jurists, it need not be about helping American jurists in particular. This American exceptionalism is especially troubling seeing that a central target for Allen here is work by three Israelis (though one with dual Israeli-American citizenship), published mostly in international journals; and seeing that Allen's paper (like this comment on it) is coming out in a journal published by a Catalan university in Spain, which states on its website: "What Quaestio facti is not: from the outset, it is important to emphasize that it is not a journal centered around the evidence law of one country or another. This is why we only publish original works that touch upon general problems related to legal evidential reasoning». See https://www.quaestiofacti.com/journal-evidential-legal-reasoning/?lang=en

Allen's American exceptionalism is rendered significantly better, I think, neither by the short disclaimer about other countries at the end of his paper nor by his willingness to describe his own paper as solipsistic.

5 At least one online dictionary defines «jurist» thus: «1. An expert in or writer on law. 2. North American: Lawyer or judge». https://www.lexico.com/en/definition/jurist

6 At times, it seems very clear that Allen has this kind of practitioner in mind. Consider (from footnote 94): «For example, I could find no American opinion in Westlaw's case database that relied on or discussed epistemic safety, epistemic sensitivity, or evidential probability». This is interesting — many 
narrow-minded practitioner anything they are after. I fail to see, though, how this amounts to any kind of objection to my theory, or to the general communal theorizing effort of which it is a part.

Does insisting on the epistemic, theoretical point of theorizing-rather than on assisting the narrow-minded practitioner-show that we theorists are not really interested in the real world? Of course not. It is the real world that we are theorizing about. Consider Allen's example of the Amazon River, whose dynamic nature he uses as an example for the dynamic nature of (American) law, purportedly a problem for my kind of theorizing about it. We theorize about the Amazon River all the time, and when we do, it seems to me, we try to reach greater knowledge and understanding of important truths about it (and about related phenomena). The Amazon River is the topic of such theorizing, and obviously, scientists studying it are deeply interested in it. That the river doesn't care about such theorizing is really neither here nor there. Analogously, if you are an evidence law theorist, you should of course pay close attention to legal practice, as it is, after all, the object of your inquiry (more about the relation between such attention and idealization below). But if your theory does well in epistemic terms, then that it may not be of use to the narrow-minded practitioner is not more a failure of your theorizing than it is a failure of a scientific study of the Amazon River that the river doesn't care ${ }^{7}$.

What about the dynamic, ever-changing nature of both the Amazon River and (American) law? Of course these objects of inquiry are dynamic, and of course a good theory of them will have to take that into account, to accommodate- and explain, and supply deeper insight into- the relevant changes. But from this obvious (and uncontroversial, I think) observation nothing follows about the nature of the sought-after theory itself. Indeed, very often good theorizing amounts precisely to finding patterns and regularity in the flux. The planets are in motion, but Kepler was after the unchanging laws that explain their motion. Even if at the end of the day he failed, surely he can't be criticized for failing to accommodate the dynamic nature of the planets. The same goes for the Amazon River, and indeed, for dynamic social systems, like the law (American or otherwise). We may, of course, fail: perhaps there is less regularity than we may have thought (and hoped). Or perhaps some posited pattern fails to accommodate the flux. But, first, all of this needs showing - with the planets, the Amazon, and the law alike—and second, such a failure will always be a price. We will seek the most general and stable theory we can find, or in other words, as much regularity in the flux as we can get. That (to an extent) a priori, normative reasoning searches for a regularity in the flux that is the law is not, then, a bug but a feature. It's a part of what theorizing is.

things are. But how is this a problem for the target views, unless Allen takes it to be a desideratum to give the narrow-minded practitioner something he or she wants?

7 Sometimes, such science will also have pragmatic payoffs, and when it does, this is great. But its value as an instance of theorizing in no way depends on whether this is so. 


\section{WEIRD HYPOTHETICAL CASES}

One of Allen's main complaints about the literature on statistical evidence is its reliance on "weird hypotheticals», like the famous Gatecrashers and Blue Bus cases. The nature of his dissatisfaction with such cases is not entirely clear to me, but it is very clear that it is grounded in the fact that such cases are too remote from actual legal practice. This is presumably why, when discussing such cases, Allen time and time again draws attention to the complexities of real life, and to the unrealistic nature of hypothetical cases ignoring them. Why is it, he asks, that only the statistical evidence is present (as is often stipulated)? How come no one in the Gatecrashers scenario keeps receipts? Who the hell represents the relevant parties, and why are they so negligent? And so on.

But what exactly is the problem that Allen sees with relying on hypothetical cases, and why is it that he thinks it's ok, in this case (but perhaps not in others) «to reject» or "to fight» the hypothetical? More than one thing, I think, is going on.

At one point (footnote 14), Allen refers to doubts coming from experimental philosophy about the use of intuitions in general, and in particular to empirical doubts about the ubiquity of Gettier intuitions in epistemology. But I don't think this is Allen's central worry, because he doesn't pursue it in detail. (Also, this worryif cogent - applies to any use of intuitions, about pretty much all kinds of cases. It's not entirely clear to me whether this is a result Allen welcomes.) Myself, I am not enthusiastic about such empirical work (see, for instance, NAGEL 2012). But for the fans, it may be significant to point out that even the high priests of experimental philosophy no longer seem to go for the simple view Allen is citing here (see MACHERY, STICH, ET AL 2015).

At another point, Allen complains: "This literature has an annoyingly imperialistic capacity to refer not just to the various authors' intuitions, but "our" and "ordinary" intuitions. Many of these do not coincide with mine, and it is interesting to see where the ones that do not are located». Many things are interesting, including studying the causal history of intuitions (which is, I think, what Allen refers to at the end of the quoted text). But Allen seems to be confused about how it is that relying on intuitions is supposed to be done in a philosophical discussion. When I rely on something being intuitively thus-and-so, it is of course only my own intuitions that I am relying on. If I use an annoyingly imperialist "we» or «our», this is just an invitation to my reader or interlocutor to think about the matter, and see if they are with me. No sanctions follow if they are not. And the probative value I assign to intuitions is always limited-they are not supposed to be a direct route to infallible truths. Rather, they are good starting points. If two theories T1 and T2 are equally good (as theories) in other respects, and T1 is and T2 is not consistent with an intuition I have, this gives me a reason to go with T1 rather than T2. This reason may be outweighed by competing reasons, and furthermore, if you don't share my intuition, you don't have that reason. Myself, because I don't do empirical work (and, as you 
already know, am not a fan of the work of this kind that I know), I will not often commit one way or another regarding «the folk's» intuitions, or «ordinary» ones. (For the record, though - there's apparently some empirical evidence showing that "ordinary» intuitions are on our side, not Allen's ${ }^{8}$.) I don't think there is anything special about this paragraph's relying-on-intuitions-101: I take it this is what all of us do, all the time, across subject matters and disciplines (even if we don't always call what we're doing by that name).

But to get to the heart of Allen's problem with weird hypotheticals, I suggest that we insist on receiving a direct, explicit, clear response to one of these cases. Faced with a weird hypothetical case, then - a case in which many factors are cleaned out by stipulation, two compared cases regarding which we use such phrases as «all other things are equal», and so on-what is his response? Take a version of the Blue Bus case, and compare two cases, such that in one there's only the statistical evidence (say, about market share), and in the other only non-statistical evidence (say, an eyewitness, or a video ${ }^{9}$ ). And I am now stipulating that all other things are equal, that there isn't any additional information, etc. The case is unrealistic, granted. But can we get a straight answer, please, about this case? Here are the main options I can think of:

(i) The case in incoherent.

(ii) In that unrealistically clean case, there is no important difference between the statistical evidence and the non-statistical evidence.

(iii) In that unrealistically clean case, there is still an important difference between the statistical evidence and the (better) non-statistical evidence.

Let's see, then: had the case been strictly speaking incoherent (i), Allen would have been entitled to reject our insistence on a (further) answer. But it's hard to see why we should think it's incoherent - where's the $p$, such that somewhere hidden in the description of the case there's both $p$ and (something that implies) not-p? At the very least, Allen has not established such incoherence. But if the case is coherent, it seems, we are entitled to an answer as between (ii) and (iii) ${ }^{10}$ - to repeat, about the case as described. How does Allen respond? At times it seems that he is mostly impatient with such cases, that he does not care about them. But this can't be the whole story—why should we care, for instance, that he doesn't? We really are owed a straight answer.

8 There's some empirical literature on the Wells Effect. See-addressing specifically our 2012 statistical evidence paper-Pinillos, Jaramillo and Horne (2019).

9 At times, Allen writes as if the only non-statistical evidence is witness testimony. («The real difference between statistical evidence and testimony lies in the trial convention of assuming reliability of witnesses until credibility is attacked. This convention obviously does not apply to statistical evidence, ...») This is not so, of course.

10 Perhaps Allen may insist that the case, like most cases, is under-described, and that different ways of filling in the details will have us landing on option (ii) or (iii) in the text. But this too has to be shown - what details are missing, and is there a coherent way of filling them in in a way that preserves the all-other-things-equal restriction? If so, what's Allen's straight answer about that new case? 
If Allen goes with (iii), it's pretty much game over. If the intuitive difference between statistical and non-statistical evidence survives the artificial cleaning out of all other factors, we are still in need of an explanation of this difference, and then all the other factors - the ones Allen likes relying on — cannot play a role in the needed explanation.

So I think Allen is best read as going with (ii) ${ }^{11}$. What, then, of the intuitions - $m y$ intuitions, that is, and my co-authors', and yours (no?), etc. - that seem to pull so strongly in the opposite direction? I think — but it's hard to tell- that Allen is putting forward debunking explanations of such intuitions; that is, he is putting forward explanations of why it is that we have those intuitions, that show them in an unflattering epistemic light, that show why we would have those intuitions even if they're misleading. This is a perfectly legitimate move, of course-and an entirely common one in the a priori reasoning genre Allen likes to say he rejects-but it doesn't come for free. It's not enough to gesture in the debunking-explanation direction. Rather, those pushing this line have to do the work. What are the details of the debunking explanation? Just how debunking is it? How is it a better explanation of the relevant intuitions compared to more vindicating ones? And having considered the suggested debunking explanation, do the purportedly debunked intuitions lose their force? Or do they retain some immediate force, but one that is lost on reflection (perhaps as perceptual impressions do in some optical illusion cases)? It's not impossible that all this work can be done. But Allen has (so far) done very little of it.

Allen insists that the Blue Bus hypothetical «contributes little of interest about the nature of juridical proof». Perhaps this explains his impatience-why even bother giving a straight answer to a question that can teach us so little, if anything at all. Perhaps he can insist, then, that he doesn't need to decide as between (ii) and (iii). $\mathrm{He}$ may even be willing to accept (iii), but insist that nothing follows from this artificial case with regard to the real-world legal phenomena. This worry raises important questions that I can only briefly address here ${ }^{12}$.

There are, in the real world, no frictionless surfaces. But no one-I think-thinks that Netwonian mechanics with frictionless surfaces is of no value, or even that it doesn't teach us anything about the real world. Some idealizations, some models, are of value, even of value in explaining the real world, despite involving such fictions as frictionless surfaces. On the other hand, if you're doing aerodynamics, then assuming away air-resistance is not an acceptable move- by assuming away air-resistance, you aren't simplifying the questions we were asking ourselves in aerodynamics. Rather, you're assuming those questions away. The difference between the two cases, I suggest, is that in the case of Newtonian mechanics a lot of its core insights and value

11 «In comparing the statistical evidence of bus distributions to testimonial evidence, the bus distribution data (assuming it maps perfectly onto accident rates) is at least as good as the testimonial evidence».

12 I discuss them in more detail in the appendix on ideal and non-ideal theory in my «Against Utopianism: Noncompliance and Multiple Agents» (2018). Also see the references there. 
survive even if all surfaces are assumed to be frictionless. When one understands something in a system with frictionless surfaces, one gains an understanding into (a partial picture of) the real world as well. Of course, one can't then proceed to apply one's conclusions or calculations (or vehicle designs) from the frictionless model to the real world as is. At the very least, adjustments will have to be made ${ }^{13}$. But to argue that no understanding about the real world is at all gained by doing Newtonian mechanics with frictionless surfaces seems ludicrous. And this is what's missing from aerodynamics without air-resistance—not much, perhaps nothing, of what's of interest and value in doing aerodynamics survives this «idealization».

Without pretending that this is an adequate discussion of idealization in philosophy (and elsewhere) ${ }^{14}$, the thing to ask now is whether discussing statistical evidence using the idealizations involved in the hypothetical cases Allen dislikes so much is more like doing Newtonian mechanics with frictionless surfaces, or more like doing aerodynamics without air resistance. And it is here that I find his complaints so unconvincing. Think about the suspiciousness of relying on statistical evidence in the real world ${ }^{15}$; now assume all these «friction»—-like factors away, so that you remain with an unrealistic clean case of statistical evidence. Does it feel like you've assumed away the problem? Of course not. These other factors are much more like friction to Newtonian mechanics, and much less like air-resistance to aerodynamics.

Of course, as elsewhere, one should not proceed too quickly from normative recommendations in the idealized friction-less world to the real world. Adjustments will have to be made. Perhaps the non-reflective practitioner cares more about these adjustments than about the theoretical insights. But if what we are after is also an understanding of "the nature of juridical proof»-its nature, that is, presumably, some central truths about it that are at least to an extent constant across a fairly wide range of circumstances and instrumental payoffs (and jurisdictions) - then of course models and hypothetical cases are of value. They may very well be indispensable.

\section{MORE ON STATISTICAL EVIDENCE}

All of this was, as I said at the outset, fully general: Sure, it applies to statistical evidence and to my views thereof, but it's not in particular about either. (For instance,

13 As I argue in ENOCH 2018, in some cases the relation between ideal theory and non-ideal theory resists this natural and simple adjustment model.

14 That such idealization is indispensable in science as well may be dialectically important in our context, because it shows that even if Allen wants to emulate science, perhaps because he's doing «naturalized epistemology», he can't escape idealization. Again, ENOCH 2018.

At least some of Allen's complaints against the use of the probability calculus are also, I think, based on a failure to appreciate the important role of idealized models.

15 When Allen insists that courts do rely on statistical evidence all the time, he conflates statistical evidence with other phenomena. See the next section. 
everything I said so far equally applies to defending Martin Smith's normic-explanation theory from Allen's related criticisms). But I want to conclude with a few more specific points, directly responding to some of Allen's more specific criticism of what we say about statistical evidence. I restrict myself to three points: about characterizing both statistical evidence and the legal treatment thereof, about Sensitivity, and about incentives.

\subsection{How does the law treat statistical evidence?}

Allen seems puzzled over what the fuss is about. It's just false, he says, that the (American) law has any problem with statistical evidence. It takes such evidence into account all the time.

This criticism fails in both directions. First, we've never claimed that courtsAmerican courts included - never admit statistical evidence. Indeed, one of our papers (ENOCH AND FISHER 2015) is precisely a discussion—in a law review—of some doctrinal complications and subtleties that it would not have been as natural to discuss in the original, more abstract and philosophical paper (Enoch, Spectre, AND Fisher 2012).

Second, and more importantly, many of Allen's examples are utterly unconvincing. In order to multiply examples, Allen lumps together all cases in which courts are happy to take into account evidence that has something to do with probabilities. But the relevant sense of statistical evidence is much, much narrower than this. We explain this in some detail in responding to Pardo (in Enoch and Spectre 2019, 183; a paper Allen refers to in a different context) who makes, we think, the same mistake:

When we-following the literature-speak of statistical evidence, we think of examples such as Blue Bus, and the phenomenon it is an example of. This is the phenomenon sometimes called base-rate evidence, sometimes market-share evidence, or sometimes naked statistical evidence... But when Pardo speaks of statistical evidence, he seems to be thinking of any evidence at all that involves a statistic. We never claimed-who would?-that any evidence involving statistics is poor or should be inadmissible, or indeed is insensitive. So Pardo's example of Tyson Foodswhere statistics were admitted in order to prove something about the circumstances, rather than as direct base-rate data for guilt or liability-is just irrelevant for our discussion. (Footnotes and page references omitted.)

As far as I can see, all of this applies directly also to Allen's examples.

\subsection{Sensitivity}

Central to our discussion of statistical evidence is the claim that in paradigmatic cases of statistical evidence such evidence is - even if not misleading - not sensitive to the truth. That is, roughly, even had the accused not crashed the gates, the court that relies on statistical evidence would have still found him guilty. Not so in the case 
of non-statistical evidence ${ }^{16}$. This, we think, is an important difference between statistical and non-statistical evidence, though it falls short of vindicating a differential treatment of these different kinds of evidence (because the law, in a slogan, shouldn't care about Sensitivity or other purely epistemic notions ${ }^{17}$ ). Here, I want to set the record straight regarding some of what Allen says about Sensitivity.

At one point, Allen insists that the difference between statistical and non-statistical evidence has nothing to do with Sensitivity. Here is what he says: «The witness' testimony is not more "sensitive" [than statistical evidence]; rather, one simply does not know what causes her mistakes and thus one does not know how they will be distributed. One form of evidence is being preferred for no other reason than ignorance of its distributional effects». But first, to repeat, we do not think that Sensitivity is something the law should care about, so this talk of preferring one kind of evidence over another misses its mark ${ }^{18}$. Second, in order to evaluate Allen's claim about the nature of the difference between testimony and statistical evidence we would need an account of counterfactuals, of causation, and more. I humbly suggest not engaging in all of those discussions here-though I would advise caution with way-too-quick assumptions that take for granted grand metaphysical claims that are hotly debated.

Allen says: "When it comes to the actual trial setting, a complex body of evidence consisting of several pieces of relevant and interrelated statistical information that converges in a way that reveals a $70 \%$ likelihood that a blue bus caused the harm is at least as good, if not better, evidence as a body of evidence that includes only the testimony of a single witness who is known to be $70 \%$ reliable in identifying the color of the bus that caused the harm». This is problematic, though, and not just because here too Allen seems to take any probabilistic evidence at all to be statistical in the intended sense. The main problem here is that whether the complex body of evidence he describes is indeed as good as (or better than) the testimony may depend on further factors about this body of evidence-perhaps including, as far as anything Allen has said, on whether the pieces of evidence in this body are sensitive. Here too, then, there is no viable objection to anything we say or think about Sensitivity.

16 Notice that the relevant question from the point of view of the court cannot be whether the relevant judgments are sensitive, because sensitivity entails truth, and the court is at that point uncertain whether the relevant judgment is true. The important point is that judgments that are based on non-statistical evidence are sensitive-if-true, whereas judgments that are based on statistical evidence are typically insensitive even if true.

17 We elaborate on and argue for this claim-in more detail than we have done in the past-in "Does Legal Epistemology Rest on a Mistake" (Enoch, Fisher and Spectre, ms).

18 Allen writes: «If what they mean is that there really is no interesting difference between the two forms of evidence, it would have been helpful, and saved a lot of time, for them to have just said that». (footnote 50). Well, we think that there are interesting differences between the two kinds of evidence, in both epistemic and incentive-related terms. But we don't think that there's a necessary difference in their reliability (the context of this footnote of Allen's), and we think that Sensitivity doesn't and shouldn't matter to the law. I think we've been pretty clear on all of these things, so that if time was wasted, this is not on us. 


\subsection{Incentives}

Allen rightly notes that on our picture what_-if anything-justifies the law's differential treatment of statistical and non-statistical evidence is not directly the epistemic Sensitivity story, but rather an incentive story. We note that accepting statistical evidence will, in some cases, erode the incentive effect that the substantive law seems to be interested in securing. The Gatecrashers case can again serve as a good example. If you are standing there, deliberating whether to buy a ticket or crash the gates, then the substantive law that makes gatecrashing a crime is supposed to give you an incentive to buy a ticket. But if you know that you may be convicted on the basis of statistical evidence alone, you know that your own action has little effect on your legal fate, or anyway, less effect than it has in a legal regime that is more suspicious of statistical evidence: After all, if so many people crash the gates, then the statistical evidence will be available against you even if you happen to buy a ticket. And if so, whatever incentive we may have hoped the criminal law supplied to buy the ticket rather than crash the gates is seriously eroded by the willingness to rely on naked statistical evidence. Notice how modest our claim here is: we're not saying that accepting statistical evidence always, necessarily, eliminates the relevant incentives. What we are saying is that the evidence law regime-and in particular, the attitude towards statistical evidence-may affect the relevant incentives, and at least often, in a counter-productive way.

Allen's main complaint about this story-on top of the complaints about «weird hypotheticals» already discussed above-is that they are unrealistic in what they require of the relevant agents. Addressing a similar incentive story about the Blue Bus case, he claims that such a story presupposes that bus drivers take the evidence regime into account in their deliberation. But they clearly don't. So the incentive story is obviously false.

This, however, is just not how incentive-explanations work, partly because this is not how incentives work. Sure, one way in which agents-people, organizations, etc.- - respond to incentives is by explicitly deliberating about the incentives' significance for them and their interests. But it is an extremely impoverished picture of action and its responsiveness to incentives (and other reasons) to think of this as the only way in which incentives may work. Incentives serve to structure choice situations, and they infiltrate actions in other ways as well. Sometimes we can point to the precise mechanisms that explain responsiveness to incentives-explicit deliberation about the incentives, imitating others who explicitly deliberate about the incentives, falsely thinking that one acts for one reason while in truth one is responding perhaps subconsciously to incentives, an organization's decision-making procedures being sensitive to incentives without any single person in them being similarly sensitive, and so on. Sometimes we can't even pinpoint the specific mechanism that renders an agent sensitive to the relevant incentives. And really, this doesn't much matter-what matters for the plausibility of incentive-explanations is not how the relevant agent is 
sensitive to the relevant incentives, but that this is so. Nothing about explicit deliberation need be implied (nor, it should go without saying, is any universal generalization about everyone being perfectly sensitive to incentives all the time).

Notice also how, if you (and Allen) reject the point of the previous paragraph, your conclusion is of much wider scope (and partly for that reason utterly implausible). Does Allen really want to suggest-on the basis of a priori reasoning, no less! - that nothing in evidence law supplies any incentive at all for primary behavior? Indeed, if his objection to our incentive story is to be taken seriously, he must reject anything remotely resembling law-and-economics explanations of pretty much anything, and vast parts of the social sciences. He may want to do this, but he's going to have to do a more convincing job arguing for such surprising claims.

\section{CONCLUSION}

I agree with Allen's general tone, according to which we should be cautious in applying lessons from epistemology - or from other philosophical sub-disciplines to legal theory. Legal doctrines of causation should probably not be sensitive to the finer points in the metaphysics of causation; if need be, we can disambiguate a legal and a metaphysical notion of causation, and take things from there. How the criminal law should treat attempts should probably not be sensitive to the finer points in the philosophy of action; if need be, we can disambiguate a legal and a philosophical notion of attempt (or of trying), and take things from there. And the same holds, of course, for epistemology and the law of evidence. This is a point I've now made in some detail, both in more general contexts ${ }^{19}$ and specifically in the context of a discussion of statistical evidence ${ }^{20}$. But nothing resembling Allen's conclusions seems to me to follow: Nothing against a priori reasoning, nothing about the illegitimacy of considering "weird hypotheticals", and at the end of the day, nothing by way of his more specific claims about statistical evidence either. Nor does it follow that philosophy has no lessons of value to a legal theorist: In fact, if Allen is sincere about his attempts to implement in legal theory the lessons of naturalized epistemology, he cannot consistently ${ }^{21}$ reject all attempts to incorporate philosophical insight into studying the law.

19 See the last section (How Not to Do Law and Philosophy) in Enoch (2012).

20 See section IV (On the Relations between Law and Epistemology) in Enoch and Spectre 2019.

21 Though perhaps - it's really hard to tell - consistency is not something he takes so seriously: "In a closed deductive and static system, inconsistencies are a problem. In complex dynamic ones, they are the order of the day." 


\section{BIBLIOGRAPHY}

Enoch, D., 2012: “Comment on Yaffe's Attempts”, Jerusalem Review of Legal Studies 6: 20 - 35.

- 2018: "Against Utopianism: Noncompliance and Multiple Agents", Philosophers' Imprint 18.

Enoch, D., Spectre, L., and Fisher, T., 2012: "Statistical Evidence, Sensitivity, and the Legal Value of Knowledge", Philosophy and Public Affairs 40, 197-224.

Enoch, D. and Fisher, T., 2015: "Sense and Sensitivity: Epistemic and Instrumental Approaches to Statistical Evidence", Stanford Law Review 67, 557 - 611.

Enoch, D. and Spectre, L., 2019: "Sensitivity, Safety, and the Law: A Reply to Pardo", Legal Theory 25, 178-199.

Enoch, D., Fisher, T. and Spectre, L. (ms): "Does Legal Epistemology Rest on a Mistake? On Fetishism, System Design, and Conscientious Fact-Finding".

Machery, E., Stich, S., Rose, D., Chatterjee, A., Karasawa, K., Struchiner, N., Sirker, S., Usui, N. \& Hashimoto, T., 2015: "Gettier across Cultures", Nous 51, 645-664.

NAGEL, J., 2012: "Intuitions and Experiments: A Defense of the Case Method in Epistemology", Philosophy and Phenomenological Research 85, 495-527.

Pinillos, N. A., Jaramillo, S. \& Horne, Z., 2019: "Asymmetric belief sensitivity and justification explains the Wells Effect", Proceedings of the 41st Annual Cognitive Science Society. 